$\xi=-1$

\title{
Development of Didactic Materials for Preschool Children with Different Sensory Perceptions
}

\author{
L.A. Komissarova ${ }^{1 *}$, V.V. Yakovleva ${ }^{2}$ \\ *MIREA - Russian Technological University, Moscow, Russia
}

\begin{abstract}
This article discusses the universal design in the subject environment. Universal design in the sphere of subject environment is a developing direction, which is necessary, especially in the field of education. Development of didactic materials for children with different sensory perceptions is proposed.
\end{abstract}

Keywords: universal design, didactic materials, wooden toys, inclusion.

\section{Introduction}

Today, special attention is paid to the development of children, since in childhood a foundation is laid for the further formation of a person's personality. Many factors contribute to personality development, but the child's activities and communication with other people are culminating.

According to research by Rosstat over the past 10 years, an increase in the number of children with disabilities has been observed in Russia. [1] This trend makes us more carefully and consciously relate to the problem of adaptation of such children.

Adaptation of people with disabilities to social realities is embodied in timely rehabilitation and effective social integration. Integration is to ensure that such children become full-fledged members of society, contribute to the surrounding space.

It is important from an early age to explain different concepts to people with disabilities. This will further overcome the social barriers, the formation of independence and the development of intelligence.

According to the classification proposed by V.A. Lapshin and B.P. Puzanov, the main categories of children with disabilities include:

- Children with hearing impairment (deaf, hard of hearing, latedeafer);

- Children with visual impairment (blind, visually impaired);

- Children with speech disorders (logopaths);

- Children with disorders of the musculoskeletal system;

- Children with mental retardation;

- Children with mental retardation;

- Children with impaired behavior and communication;

- Children with complex disorders of psychophysical development, with so-called complex defects (deaf and blind, deaf or blind children with mental retardation). [2]

This article proposes to get acquainted with didactic materials for children with sensory impairments (hearing and vision), as well as healthy children.

Sensory impairment in children is a complex cerebral disorder in which a child misinterprets everyday sensory information, which can lead to problems with motor coordination, speech, behavior, learning, etc. This is due to the processing, integration and modulation of sensory information from the environment and from your own body. [3]

Preschool age is an important stage in a person's life. During this period, visual-effective thinking is formed and formed. The preschool age is also called the "age of play". At this time, the child best learns information in a playful way, so you should look for ways of conveying information that will be playable, you also have to take into account that the child should take an active part in the game process, and not be a passive observer. violations. Together with their age group, these children can be helped to develop a variety of skills.

At the moment, in Russian institutions of preschool and school education there is an acute shortage of didactic materials for children with disabilities, inclusive didactic materials are even more rare and more likely to be exotic. There is also a request from correctional educational institutions for affordable training materials of low cost. This indicates the need to address this issue and emphasizes the relevance of this topic.

The aim of the work is the development of design and manufacturing technology of educational games for the joint training of children with different physical capabilities.

The task is to develop game methods of studying the world for preschool children with different sensory perceptions, which, along with development of the main sense organs, will give the child an idea of the world around.

\section{Research method}

Design, like other disciplines / sciences, does not stand still and develops, following the trends of the modern world. The global trends include the improvement of people's lives, despite their physiology. In this area, many developments are being carried out, including for the mutual convenience of using objects and design objects for various groups of people. This section of the project activity is called universal design. Such a design includes not only the accessibility of the architectural environment for all categories of citizens, but also subject and information accessibility, tactile adaptations.

The design and formation of the objective environment are increasingly based on the principles of universality, which consist 
in providing equal conditions and opportunities for people of different social, age, and gender groups; for people with limited mobility, with different levels of sensory perception, etc. [four] Each type of sensory impairment has its own main channel of perception of information. For children with visual impairment, the touch becomes the main one; for children with hearing impairment, the visual channel dominates. In order to make it interesting for different children, it is necessary to act on most types of perception at the same time.

At the beginning of work, different approaches to this problem were considered, for example, using several ways to present information simultaneously: Braille for the visually impaired, sign language for children with hearing impairment in combination with traditional methods for healthy children. As a result, cubes were developed to jointly teach children with different sensory abilities.

The idea of creating learning cubes is not new, but it was decided to approach the development from a different angle - the angle of universal design.

Each cube on its three faces contains unique information about a specific figure, and information related to the score is plotted on each of the faces.

On the first face there is a number and its designation in Braille (Fig. 1, 1a, 1b).

On the second, a convex pattern with the number of objects indicated on the first face (Fig. 1, 2a, 2b).

At the third - the same figure as the first, but outlined in sign language (Fig. 1, 3a, 3b).

The fourth, fifth, and sixth positions are "+", “-”, and "=", with instructions for their style in Braille. These designations will be unchanged on all cubes (Fig. 1, 4a, 5a, 6a, 4b, 5b, 6b). [5]

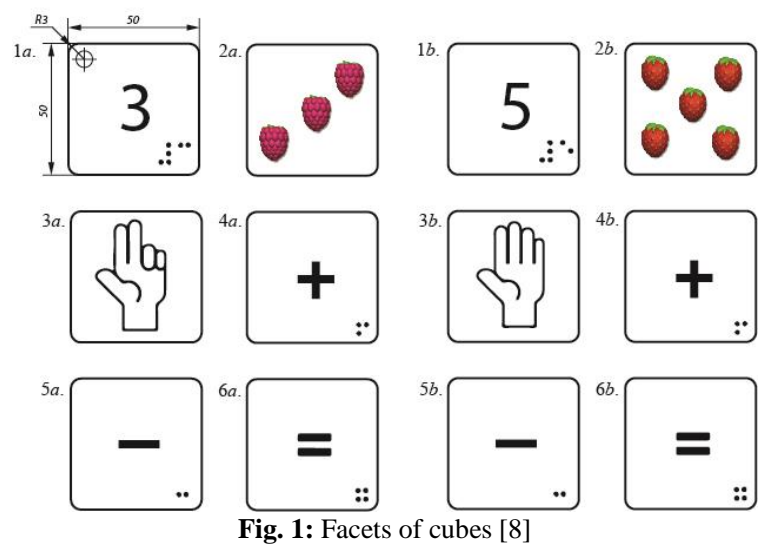

As we dive into this topic, new ideas began to emerge for the joint training of children with different sensory capabilities. It was decided to work out other areas, for example, how to jointly acquaint children with the concepts of space, the world and its diversity. For this, the frame-insert toy was chosen as the didactic material.

The frame insert is a panel with grooves cut out in it for loosefitting parts of various shapes that correspond to a certain notch on this panel. This is a fairly well-known and popular toy, but mainly designed for ordinary children, without developmental features. It was decided to adapt these toys and make them available to all categories of children.

A distinctive feature of the developed insert frames is their surface. The surface is embossed with a clear transition from one puzzle element to another, so that when you touch, there is a difference in texture. Also focus on color. For this purpose, fabrics pasted on the base of the frame and liners are used. The raw materials and materials used for this should have a hygienic assessment and be confirmed by certificates.

Fabrics are used with a special, distinctive texture from each other. For example: linen, satin, denim, fleece, velvet, corduroy. Each part of the toy has its own specific fabric, but for mass production, it is desirable to use fabric imitation to simplify the production process.

The atlas is used to refer to the oceans, since this fabric feels like cool water. The advantages of satin include the fact that it is durable wear-resistant material, retains a presentable appearance for a long time, it is safe, because does not contain allergens.

Fleece is used for Antarctica to explain to children that it is cold and it is necessary to dress warmly. This is a knitted material, an artificial analogue of sheepskin. Soft, but dense and warm material, at additional processing can have protection against microbes, is steady against attrition.

Velvet is used to designate Europe, the homeland of this fabric. (Fig.2) This fabric with a slight sheen and overflow contains cotton. The material is hypoallergenic, retains its appearance for a long time, soft and dense

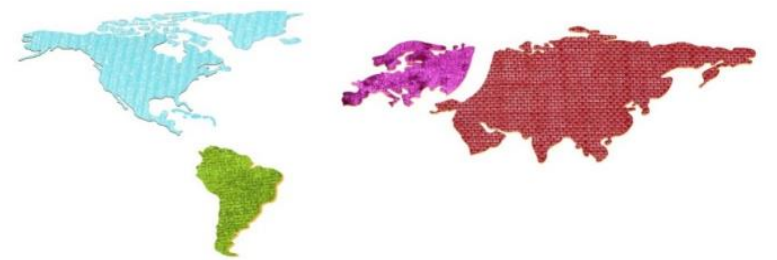

Fig.2: Designation of parts of the world. [eight]

Velvet with a different size of the scar is also used to designate continents of North and South America. Different types of velveteen make it clear that they are different continents, but at the same time one part of the world, because tactile sensations have a common structure. This fabric has a distinctive texture, which allows it not to be confused with other fabrics. This material is strong, durable, warm, pleasant to the touch. [6]

Children, while learning about the world, are in close contact with various objects, especially toys. Therefore, we must be especially careful with the choice of materials for their manufacture. After all, the child first of all strives to check the toys for taste and strength.

\section{Results and analysis}

As a result, cubes for learning to count (Fig. 3) and the "World around" insert frame (Fig. 4) were designed for children with different sensory perception.

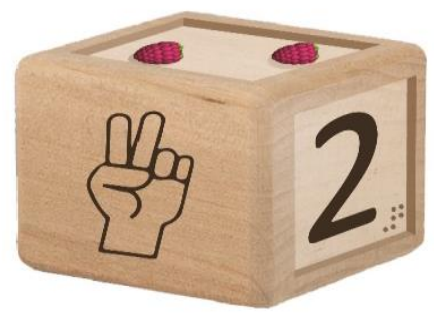

Fig.3: Cube for learning account [8]

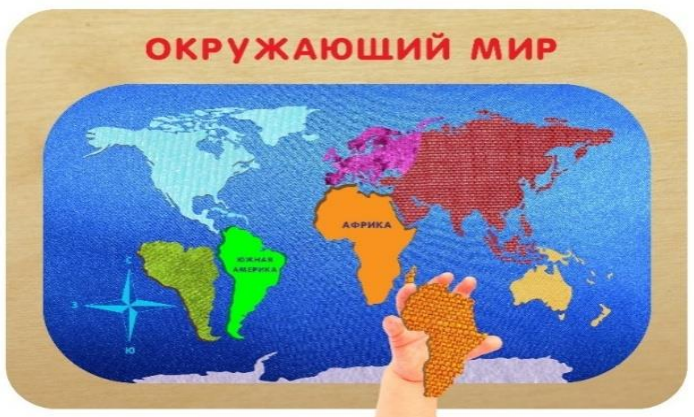

Fig.4: Frame inserts "The World". [8] 
It is preferable to make cubes from solid wood, although other materials can be used, but wood is an environmentally friendly material. Wood is safe, children can use cubes without the risk of allergies or poisoning, as sometimes happens when using lowquality plastic toys.

Wooden cubes will not lose their shape, they will not break, they will not break, which once again underlines the advantages of wood over other materials, for example, plastic or textiles.

Wood is a traditional strong and durable material. Wooden toys are timeless, they have been relevant for many centuries, and so far their popularity has not faded, as in almost all traditional cultures there are toys made of wood. Often, wooden toys are passed on for generations, because they are made of high-quality wood and durable, they are difficult to damage.

The main advantages of this material can also be noted that the processing of wood is almost no harm to the environment, since wood is a living natural material, its resources are recoverable.

The tree radiates the energy of nature, it has a natural color and smell, it is warm and pleasant to the touch, which together has a beneficial effect on the development and health of the child.

Wooden cubes are a simple form that can fully convey the correct information about the basic rules of counting, help naturally develop the playing skills of children, their imagination and mental abilities.

The panel insert gives children the opportunity not only to view, but also to feel the locations of the continents with the help of removable parts. Children can use such a map as a puzzle, selecting and inserting inserted parts into their specific places on the panel. Children do not just make puzzle pieces that fit the shape, but also build a holistic view of the world map for themselves.

For the manufacture of the developed frame liners, wood was chosen, or rather wood material - plywood. You can take other materials, for example, plastic or metal, but unlike them, plywood during operation will not lose its shape, will not break, which is typical for plastic, plywood is not as heavy and cold as metal. Plywood does not respond to heat, has a natural smell, pleasant to the touch. All this has a beneficial effect on the child's perception of the information that the toy transmits.

The developed map gives an idea to children about such concepts as the north-south-west-east, parts of the world, and the location of continents. This approach can be used to explain life, animal species, a wider disclosure of geographical concepts by region and country, etc. . A child can be introduced to the diversity of the world: first, with plants divided into subspecies; secondly, with a wide range of animals and representatives of the globe; thirdly, with geographical distribution over various natural zones and continents, as well as with geographical or historical objects, etc. After the children become well-versed in this toy map, they can be introduced to more complex concepts like time zones and climatic zones. Perhaps someone will consider it premature, not by age, but as Vygotsky wrote L. S.: "Only that training is good, which runs ahead of development." [7, p.386]

Such toys contribute to the generation of spatial thinking, develop the skill of step-by-step solution of the proposed tasks, contribute to fixing attention.

With the help of the developed didactic materials, it is possible to solve such important tasks for the development of a child as:

-development of fine and large motor skills;

- motivation for activity, curiosity;

- development of a sense of touch;

- learning numbers in Braille (for blind children) and in sign language (for deaf and dumb children);

-perception of thin color shades and transitions (for sighted children);

- development of memory, logic, imagination.

At the moment, when the consumer market is oversaturated with goods, the quality of products is of great importance. Parents began to pay great attention to children's products, more and more attention is paid to the materials from which it is made.
Environmental friendliness and safety come to the fore. Especially these aspects are important for the unformed body of the child.

\section{Conclusion}

Despite the fact that a large number of new games and toys are produced every year, which are replete with all sorts of details and functionality, it is preferable for children to still have toys that give the child freedom of creativity and meaningful activity. Toys that use complex mechanisms do not lead to proper results. With such toys, the creative cognitive process is almost not realized, the child becomes an outside observer (contemplative), does notshow imagination and ingenuitywhich is so necessary for the development of children. An important part of game is the creative process, because the child develops only if he learns to independently overcome emerging problems, and does not repeat some kind of skill and assimilates ready-made knowledge. For a child, those toys that encourage action, contribute to communication and empathy are good.

Developed didactic materials with a universal design will allow children with disabilities to play with ordinary children, at the same time they will broaden their horizons, because development of a child is directly dependent on its environment. Also, developing toys will help children to perceive and absorb new knowledge more easily, to love the learning process and the thought process, which in future will significantly simplify the life of the child, despite his physical indicators.

\section{References}

[1] Federal State Statistics Service [Electronic resource] - URL: http://www.gks.ru/wps/wcm/connect/rosstat_main/rosstat/ru/statisti cs/population/healthcare/\# (appeal date 12.10.2018) .

[2] Parishioners A.M., Tolstykh N.N. Children without family. - M., 1990. - $160 \mathrm{p}$.

[3] Sadovskaya Yu. E., Blokhin B. M., Troitskaya N. B., Pronicheva $\mathrm{Yu}$. B. Disorders of sensory processing in children / Sadovskaya Yu. E., Blokhin B. M., Troitskaya N. B., Pronicheva Yu. B. // Medical business. - 2010. № 4. - p. 24-28.

[4] M. Sokolova, Current Problems of the "Technology of Artistic Processing of Materials" direction / M. Sokolova // Russian technological journal. - 2017. - № 1 (15). - p. 50-56.

[5] Komissarova LA, Yakovlev V.V. Development of methods for teaching children with different physical abilities / Komissarova LA, Yakovleva V.V. // Collection of reports of the conference "Universal Design - Equal Opportunities - Comfortable Environment, 2018" of the Physics and Technology Institute MIREA of the Russian Technological University. - M .: MIREA, 2018. - P. 23-27.

[6] Komissarova LA, Yakovlev V.V. Development of a learning insert for the "World around" for children with various physical capabilities / Komissarova LA, Yakovleva V.V. // Collection of reports of the conference "Universal Design - Equal Opportunities Comfortable Environment, 2018" of the Physics and Technology Institute MIREA of the Russian Technological University. - M .: MIREA, 2018. - P. 28-33.

[7] Vygotsky, L. S. Pedagogical psychology. - M .: Pedagogy, 1991. p. 480.

[8] Personal archive Yakovlevoj V.V. 